\title{
ROUTING URBAN TRANSPORT NETWORK WITH WEIGHING ARCS FUZZY NUMBERS AND APPLICATION IN EMERGENCY MEDICAL AID
}

\author{
Petya Stoyanova \\ "Todor Kableshkov" University of Transport \\ Geo Milev 158, 1574 Sofia, Bulgaria \\ phone: +359 (2) 9709-319, e-mail: petia_8@abv.bg
}

\begin{abstract}
The paper examines the problem of traffic assignment at certain routes in the urban transportation network based on the first principle of Wardrop - (UE - users equilibrium), and the second - (SE - system equilibrium) - the average time for the system is minimal. The network is represented as a directed graph with Fuzzy arcs' weights and travel times as a function of traffic flows. The algorithm of route selection is based on the incremental approach to release part of the flow for certain destination along the shortest route determined with considering the presented Fuzzy weights. The modified Dijkstra's algorithm is used according to which the arcs' weights are represented as Fuzzy numbers. The paper focuses on the routing of an emergency care ambulance depending on the coverage of the outpatient emergency care centre on the area of the received call and taking it back into the headquarters after the patient has been driven to the closest hospital. The coverage of the regions in the city of Sofia has been defined in advance by applying the well- known mathematical model of selecting the centres location through implementing the task of coverage (set covering problem), a task of mixed integer and linear programming. The target function and constraints and binary variables are defined in the Solver Add-in.
\end{abstract}

Keywords: route, transportation networks, fuzzy weight arcs, emergency medical aid.

\section{INTRODUCTION}

The problem of searching the shortest path is very common and is widely studied on graph theory and optimization areas. Transport networks most often presented in the literature as a directed graph $\mathrm{G}(\mathrm{V}, \mathrm{E})$, with sets of nodes $\mathrm{V}=\{1, . . \mathrm{N}\}$ and the $\operatorname{arcs} \mathrm{E}=\{1, . . \mathrm{M}\}$. The practical application in various transport and logistical problems associated with the achievement of the best path is connected with many algorithms which are more or less effective, depending on the particular case. Most of these path finding algorithms are ones for to the shortest path from a source node to the other node or to all other nodes in the graph. In different models for traffic forecasting after receiving the forecasting matrices of correspondences (O-D) it is necessary to make the appointments of flows on specific routes in the transport network. The most often used method is so-called aggregate value of the determined flows in an arc in the transport network. The literature describes various methods for the attachment of traffic flows: all or nothing - each correspondence is distributed by the shortest path-Shortest Path Problem (with a minimum value / time, etc.); under: 1st principle of Wardrop for 'users' equilibrium' (UE), and the 2nd for 'system equilibrium'(SE) - the average time for the system is minimal, as shown in [3], [8]. One of the most common approaches is the incremental approach [2]. It could be briefly defined as follows: for each O-D correspondence from the ith node of $\mathrm{j}$-th node, part of $\mathrm{k}$-th mode of transport is directed $f_{i j}^{k}$ through the shortest path $\mathrm{P}$ (i-> j), set by the well-known algorithms of Dijkstra, Floyd, etc. When a part of the flow passes given arcs of the network, they change their length, due to nonlinear dependence to the

IRTIIE Vol. 5, No. 1, 2017 ISSN 1314-8788 (print), ISSN 1314-8796 (online), doi: 10.15547/artte.2017.01.002 


\section{AR'TIE

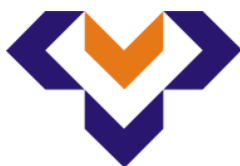 \\ Ipplied Researlohes in Technics, Technologies ind Bductition \\ Journal of the Faculty of Technics and Technologies, Trakia University https:///sites.google.com/a/trakia-uni.bg/artte/}

"length". During the next iteration of the other correspondence $(z, I)$ it is passed on new part $\Delta f_{z l}^{k}$ through the shortest path. All O-D correspondences are carried out by adjusting the values of all the arcs of the Shortest path. Shortest-Path Problems play an important role for the attachment of matrices of correspondences in routing in urban transportation networks.

\section{METHODS}

For realization of the problem with the inclusion of the evaluation of uncertainties in algorithms for finding the shortest path between two or between all the nodes - length of the arc of the network may represent the time or costs that are variable (non- deterministic). In literature there are different approaches to accounting for variability: interval estimation [1] and fuzzy numbers. The fuzzy sets theory was introduced by Zadeh [13]. This is a method for modeling the type of of instability associated with ambiguity. In this paper is used proposed in [5] modification of Dijkstra's algorithm, as permanent marks of each vertex (the shortest distance from vertex source) also fuzzy numbers.

Despite the intensive development of the theory of fuzzy sets. There is no single formula formulation of the problem [13],[5],[11],[6], due to various assumptions, aims and forms of fuzzy numbers. In this paper an approach is used for finding the shortest path from $s$ to all other nodes of the graph, similar to that in [13].

This paper is examined improvement of the incremental approach in [7] and [8], , as is examined uncertainty in the inclusion of deterministic assessments to determine the shortest routes.

\section{DEFINITIONS AND METHODS}

Two approaches to distribution (appointing of routes) matrix conversations with deterministic evaluate the function of the cost depending on the flows in each arc are presented.

By following the exhibition in [7], the transport network is presented as Connected graph $G$ $(\mathrm{V}, \mathrm{E})$, comprising a set $\mathrm{V}$ of vertices, and a set $\mathrm{E}$ of arcs (sections of the road network), with $\mathrm{N}$ nodes and $\mathrm{M}$ oriented arcs. At a matrix of correspondences (O-D matrix) $\mathrm{T}$ with elements of traffic Tij. The task is reduced to correspondents, where unit of flow passing through arcs (sections) in network of minimal cost.

The target function:

$$
Z=\sum_{k=1}^{M} f_{k} c_{k}\left(f_{k}\right) \Rightarrow \min
$$

where $f_{k}$ It is summary flow of correspondences, passing through the arc $\mathrm{k}$, and $c_{k}\left(f_{k}\right)$ the cost (time) for passing the one unit flow through arc $\mathrm{k}$.

When not take into account the index $k$, for each arc can be used as known function BPR;

$$
c(f)=t(f)=t_{0}\left\{1+\alpha\left(\frac{f}{u}\right)^{\beta}\right\}, \quad \alpha=0.2 \quad \beta=4 \text {; }
$$

$t_{0}$ - time travel at speeds of free movement; $u_{\text {- }}$ a throughput of the arc.

At fixed cost $c_{k}\left(f_{k}\right)=$ const , the problem is solved by known methods of linear programming. Generally, cost $c_{k}$ nonlinear depend on the volume of flow in the arc $f_{k}$, which is the task of nonlinear programming. Staging of the problem in [6] e as follows: $a$ is the initial state of the

IRTIIE Vol. 5, No. 1, 2017 ISSN 1314-8788 (print), ISSN 1314-8796 (online), doi: 10.15547/artte.2017.01.002 


\section{ARTIIE

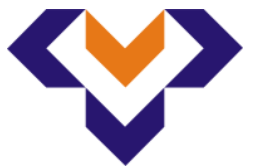 \\ Ipplied Researlohes in Technics, Technologies ind Bductition \\ Journal of the Faculty of Technics and Technologies, Trakia University https:///sites.google.com/a/trakia-uni.bg/artte/}

system, i.e. the elements of the graph accumulate distributable flows $f_{k}^{(0)}$. Calculate values (times) $-c_{k}\left(f_{k}^{(0)}\right)$ and are defined in arcs $e_{k} \in E$ of the network $\mathrm{G}(\mathrm{V}, \mathrm{E})$. Found are the shortest routes for all correspondence and recorded in separate massifs. In certain step is passing on part of the correspondence on the shortest path, calculated increase of arc's flow of the path, recalculated costs for the next iteration $c_{k}\left(f_{k}^{(1)}\right)$ and again entered in graph of the network. Again find the shortest routes and for each iteration is recalculated Tij, while not be distributed all O-D matrix.

A similar algorithm in [8], the network is "loaded", alternately in small steps and after each step "recalculated" values the shortest path from a vertex $(O)$ to a vertex $(D)$, and many other approaches have been presented in [8].The basis of the both described algorithms repeate application of algorithm for finding the shortest path from a source node to the other nodes is or to all other nodes in the graph. This is a classical algorithm of insertion of "label" of Dijkstra, at given values determined length (time, cost) of arcs in graph $\mathrm{G}(\mathrm{V}, \mathrm{E})$.

Therefore, one of the variants to be examined the shortest path problem with not deterministic "length" is a modification of the algorithm of Dijkstra, or to use known algorithms for finding k- shortest paths [12], [3] with the inclusion of an uncertainty

In the next paragraph will be present an approach to solve the shortest paths problem, with lengths of arcs in the graph - fuzzy numbers, which is described in [11]. It will be considered only triangular fuzzy numbers $(a, b, c)$. The modified Dijkstra's algorithm with arc lengths fuzzy numbers and are used example data by emergency medical aid in Sofia.

\subsection{Triangular Fuzzy Number}

Given is an Acyclic directed graph Figure 1. Triangular fuzzy number A Figure 2, which can be of value $(a, b, c)$ is defined by membership function which assigns to each object a grade of membership ranging between zero and one for a given value $(x)$ to a fuzzy set $\mu A(x)$. This is illustrated in the formula (3). In the general case - a-min, b-mode, c-max.

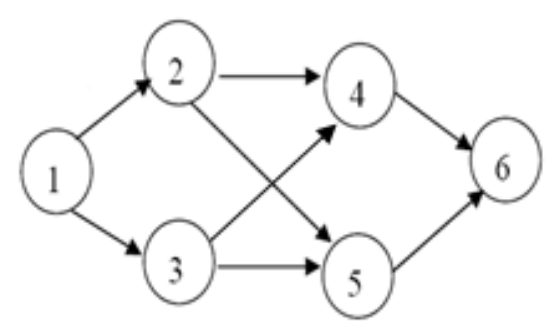

Figure 1. Acyclic directed graph

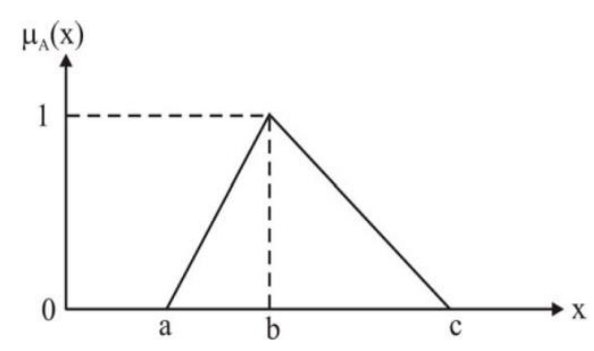

Figure.2. Membership function

\subsection{Fuzzy Shortest Path Length Algorithm [11]}

Step 1: All the possible paths Lengths $\mathrm{Li}$ from $\mathrm{i}=1,2 \ldots \mathrm{n}$ where $L_{i}=\left(a_{1}^{\prime}, b_{1}^{\prime}, c_{1}^{\prime}\right)$. 


\section{IRTTL} Ipplied Researlohes in Technics, Technologies ind Bductation Journal of the Faculty of Technics and Technologies, Trakia University https://sites.google.com/a/trakia-uni.bg/artte/

$$
\mu A(x)=\left\{\begin{array}{ll}
(x-a) /(x-b) & , a \leq x \leq b \\
(c-x) /(c-b) & , b \leq x \leq c \\
0 & , \text { otherwise }
\end{array}\right\}
$$

Step 2: Initialize $L \min =(a, b, c)=L_{1}\left(a_{1}^{\prime}, b_{1}^{\prime}, c_{1}^{\prime}\right)$.

Step 3: Initialize $\mathrm{i}=2$.

Step 4:

$$
\begin{aligned}
& b=\left\{\begin{array}{l}
b ; \quad \text { ако } \quad b \leq a_{i}^{\prime} \\
\frac{\left(b * b_{i}^{\prime}\right)-\left(a * a_{i}^{\prime}\right)}{\left(b+b_{1}^{\prime}\right)-\left(a+a_{1}^{\prime}\right)} ; \quad \text { ако } \quad b>a_{i}^{\prime}
\end{array}\right. \\
& a=\min \left(a, a_{i}^{\prime}\right) ; \quad c=\min \left(c, b_{i}^{\prime}\right) ;
\end{aligned}
$$

Step 5: Set $L \min =(a, b, c)$ as calculated in Step 4 .

Step 6: $i=i+1$.

Step 7: If $i<n+1$, go to in Step 4 .

Similarly is defined in fuzzy number $\mathrm{B}$, which can be of value $(a 2, b 2, c 2)$ real numbers. Then the fuzzy sum of these two is: $A+B=(a 1+a 2, b 1+b 2, c 1+c 2)$.

Fuzzy shortest path length algorithm is ilusreded with the example of graph $G(V, E)$ from Figure 1 with fuzzy numbers of arcs from Table 2.

\section{RESULTS}

The cars of emergency medical aid with special regime of movement under the Law on Road Traffic enjoyed advantage on the road. Practically ambulances pass crossroads included sound and light, when perform signal to a patient with a life-threatening the situation or is transported in a critical state to the hospital. For example, case in which the ambulance is a special regime of movement to the patient with life-threatening the situation i.e. code red (8 min.) by the standards of emergency medical aid. Complying with the location and the number of emergency centers and their coverage area within the specified by standards time framework, where implementing the task of coverage (set covering problem) [9].

After receiving emergency call the ambulance from additional emergency center that cover the region is assigned to service: access to patient location, transportation to the nearest suitable hospital emergency department and return to central emergency center.

Therefore, the length of each of arcs in the urban transportation network has three distances, which are presented as Fuzzy numbers. The objective is to determine the shortest path using a combination of the two described above approachs. The example is presented as each of the node in the transport network corresponds to:

1 - Additional medical center; 2 - Patient; 3 - Patient;

4 - Hospital; 5 - Hospital; 6 - Central Emergency Medical Center.

IRTTL Vol. 5, No. 1, 2017 ISSN 1314-8788 (print), ISSN 1314-8796 (online), doi: 10.15547/artte.2017.01.002 


\section{IRTIIE}

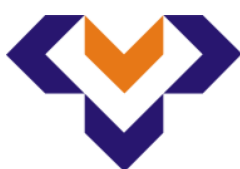

Ipplied Reseirlores in Teednics, Technologies ind Education

Journal of the Faculty of Technics and Technologies, Trakia University https:///sites.google.com/a/trakia-uni.bg/artte/

In Table 1 is shown the location of each of the nodes with geographic coordinates, which are converted decimal numbers. The geographic coordinates are converted to decimal numbers, by using same formula (5) for Latitude and for Longtitude.

$$
1^{\circ}+\frac{1^{\prime}}{60}+\frac{1^{\prime \prime}}{3600}=\text { decimal number; }
$$

In Table 2 are presented each arcs between the vertex and their lengths with values in the general case - a-min, b-mode, c-max.

Table 1. Coordinates

\begin{tabular}{|l|c|c|}
\hline Vertex & Latitude & Longtitude \\
\hline 1 & 42,670092 & 23,347919 \\
\hline 2 & 42,679397 & 23,381289 \\
\hline 3 & 42,648317 & 23,401267 \\
\hline 4 & 42,658847 & 23,415283 \\
\hline 5 & 42,660164 & 23,371992 \\
\hline 6 & 42.70446 & 23.332764 \\
\hline
\end{tabular}

Table 2. Legth of arcs

\begin{tabular}{|c|c|c|c|c|}
\hline \multicolumn{2}{|c|}{ Arc (i, j) } & \multicolumn{3}{|c|}{ Length Lij } \\
\hline $\mathrm{i}$ & $\mathrm{j}$ & $\mathrm{a}$ & $\mathrm{b}$ & $\mathrm{c}$ \\
\hline 1 & 2 & 4,3 & 4,6 & 6,2 \\
\hline 1 & 3 & 7,7 & 8,4 & 8,5 \\
\hline 2 & 4 & 2,5 & 2,7 & 3,9 \\
\hline 2 & 5 & 3,7 & 4,4 & 5,1 \\
\hline 3 & 4 & 5 & 5.8 & 7.4 \\
\hline 3 & 5 & 4,5 & 4,9 & 5,2 \\
\hline 4 & 6 & 6,2 & 6,4 & 7,5 \\
\hline 5 & 6 & 6,9 & 7,7 & 9,7 \\
\hline
\end{tabular}

Step 1: Determined the following 4 possible paths from 1 to 6 :

$\mathrm{P} 1: 1-2-4-6->\mathrm{L} 1=(4.3+2.5+6.2,4.6+2.7+6.4,6.2+3.9+7.5)=(13,13 \cdot 7,17.6)$

P2: $1-2-4-5-6->\mathrm{L} 2=(14.9,16.7,21)$

P3: $1-3-4-6->L 3=(18.9,20.6,23.4)$

P4: $1-3-5-6->L 3=(19.1,21,23.4)$

Step 2: $\mathrm{Lmin}=\min (\mathrm{L} 1, \mathrm{~L} 2, \mathrm{~L} 3<\mathrm{L} 4)->\mathrm{L} 1=(13,13.7,17.6)$

Step 3: i = 2;

Step 4: Compute $(a, b, c)$ :

$$
\begin{aligned}
& b=\left\{\frac{(16.7 * 13.7)-(14.9 * 13)}{(16.7+13.7)-(14.9+13)}=14 ; b>a_{i}^{\prime}\right. \\
& a=\min \left(a, a_{i}^{\prime}\right)=\min (13,14.9)=13 ; \\
& c=\min \left(c, b_{i}^{\prime}\right)=\min (17.6,16.7)=16.7 ;
\end{aligned}
$$

IRTIIE Vol. 5, No. 1, 2017 ISSN 1314-8788 (print), ISSN 1314-8796 (online), doi: 10.15547/artte.2017.01.002 
$\mathrm{L} 2=(13,14,16.7)$

Step 5: $\mathrm{Lmin}=\min (\mathrm{L} 1, \mathrm{~L} 2<\mathrm{L} 3)->\mathrm{L} 2=(13,14,16.7)$

Step 6: $i=3(i=2+1)$;

$$
\begin{aligned}
& b=\left\{\frac{(14 * 20.6)-(13 * 18.9)}{(14+20.6)-(13+18.9)}=15.9 ; \quad b>a_{i}^{\prime}\right. \\
& a=\min \left(a, a_{i}^{\prime}\right)=\min (13,18.9)=13 ; \\
& c=\min \left(c, b_{i}^{\prime}\right)=\min (17.6,20.6)=17.6 ;
\end{aligned}
$$

$\mathrm{L} 3=(13,15.9,17.6)$

Step $7: \mathrm{i}=4(\mathrm{i}=3+1)$;

$$
\begin{aligned}
& b=\left\{\frac{(14 * 21)-(13 * 19.1)}{(14+21)-(13+19.1)}=15.9 ; \quad b>a_{i}^{\prime}\right. \\
& a=\min \left(a, a_{i}^{\prime}\right)=\min (13,19.1)=13 ; \\
& c=\min \left(c, b_{i}^{\prime}\right)=\min (17.6,21)=17.6 ;
\end{aligned}
$$

$\mathrm{L} 4=(13,15.9,17.6)$

To calculate Step 7 of the algorithm, i.e. to found Euclidean distances between all path lengths and Lmin applying the formula (4). Therefore are calculated Euclidean distance:

P1: 1-2-4-6, $\mathrm{Li}=(13,13.7,17.6)$ and $\operatorname{Lmin}=(13,14,16.7)$.

$$
(L i, L \min )=\sqrt{(13-13)^{2}+(13.7-14)^{2}+(17.6-16.7)^{2}}=0.96
$$

Step $8:$ At $i=5$. The procedure stops.

And finally the fuzzy shortest path length $\operatorname{Lmin}=(13,14,16.7)$ is calculated. The detail about calculate the shortest path is shown in paragraph 4.1 .

\subsection{An Algorithm for Searching the Shortest Path}

We aim at determining the fuzzy shortest length Lmin and the shortest path needed to traverse from source to destination. By combining the fuzzy shortest length method with similarity measure, the new algorithm is as follows in Table 3.

The next step, we compute the similarity degree $\mathrm{S}(\mathrm{Lmin}, \mathrm{Li})$ between $\mathrm{Lmin}$, and $\mathrm{Li}$ for $\mathrm{i}=$ $1,2,3$ by means of similarity measure:

$$
S(A, B)=\sum_{k=1}^{m}\left[1-/ A\left(x_{k}\right)-B\left(x_{k}\right) /\right] / m
$$

On executing the above algorithm on the example network of Figure 2. The first two steps have been already calculated in section 4 . 


\section{AR'T'IE

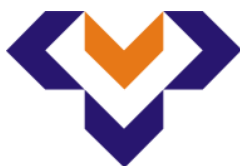 \\ Ipplied Researlohes in Technics, Technologies ind Bductition \\ Journal of the Faculty of Technics and Technologies, Trakia University https://sites.google.com/a/trakia-uni.bg/artte/}

Table 3. An algorithm for the fuzzy shortest path

\begin{tabular}{|l|l|}
\hline 1 & $\begin{array}{l}\text { Find out all the possible paths from } \\
\text { Source node S to Destination node D } \\
\text { and compute the corresponding path lengths } \\
\mathrm{Li}, \mathrm{i}=1,2 \ldots . . \mathrm{n} .\end{array}$ \\
\hline 2 & $\begin{array}{l}\text { Compute Lmin by using fuzzy shortest } \\
\text { path length procedure (Table 1) }\end{array}$ \\
\hline 3 & $\begin{array}{l}\text { Find the Euclidean distance di for } \mathrm{i}=1,2 . \mathrm{n} \\
\text { between all the possible path and Lmin }\end{array}$ \\
\hline 4 & $\begin{array}{l}\text { Decide the shortest path with the path } \\
\text { having lowest Euclidean distance. }\end{array}$ \\
\hline
\end{tabular}

In order to compute the accuracy in similarity degree, we should let a generic element $U$ denoted by $\mu \mathrm{i}=(\mathrm{i}=1,2 \ldots 10)$, we will discuss in detail as follows:

From section 4 we have four possible paths lengths in Figure 2 as:

$\mathrm{P} 1=(13,13.7,17.6)$

$\mathrm{P} 2=(14.9,16.7,21)$

$\mathrm{P} 3=(18.9,20.6,23.4)$

$\mathrm{P} 4=(19.1,21,23.4)$

And minimum path length is:

$\operatorname{Lmin}=(13,14,16.7)$.

Now to compute step 3 of algorithm in Table 3 i.e. to find Euclidean distance between all path lengths and Lmin.

For path 1 length is $(13,13.7,17.6)$ and $\operatorname{Lmin}$ is $(13,14,16.7)$. Therefore calculating Euclidean distance:

$$
d(\text { path } 1, L \min )=\sqrt{(13-13)^{2}+(13.7-14)^{2}+(17.6-16.7)^{2}}=0.96
$$

In the similar way after computing the Euclidean distance we get $d($ path $2, \operatorname{Lmin})=4.77$, $\mathrm{d}($ path $3, \operatorname{Lmin})=10.10$ and $\mathrm{d}($ path $4, \operatorname{Lmin})=10.41$.

Next, we want to decide the shortest path by examining the Euclidean distance $d$ between Lmin and di for $i=1,2,3$. And from the above calculations we can see that path 1 has the least Euclidean distance, and one can choose path 1-2-4-6 as the shortest path.

\section{CONCLUSION}

In this paper the main objective is shown how given uncertainty is reflected in the shortest path between two nodes. The algorithm for determining them is an important part of the algorithm for distribution of correspondence from the matrix O-D. The application of two known approach presents the concrete routes in real transport network. The method is explained with this an example. Application is made with the help of example data by emergency medical aid in Sofia. This optimization of the lengths of arcs with fuzzy numbers would be useful in life-threatening cases of emergency medical aid. The stages are realized with choice of service hospital with an emergency room on a criterion the shortest path length.

IRTITE Vol. 5, No. 1, 2017 ISSN 1314-8788 (print), ISSN 1314-8796 (online), doi: 10.15547/artte.2017.01.002 


\section{IRTIL $<>$}

Ipplied Researlohes in Technics, Technologies ind Bductition

Journal of the Faculty of Technics and Technologies, Trakia University https://sites.google.com/a/trakia-uni.bg/artte/

\section{REFERENCES}

[1] Hossain A., Dimitrov S., Madjarski E. The Interval Shortest-Route Problem on Sofia Transportation Network, Bulgarian academy of sciences, problems of engineering cybernetics and robotics, 2009, 61.

[2] Karagyozov K., Razmov T., Yu. Varadinova-Milkova. Izpolzvane na integralniya podhod pri optimiziraneto na strukturata i elementite na logistichnite verigi i pri upravlenie na logistichnite sistemi. ALMANAC of University of Transport, Sofiia, 2012.

[3] Karagaozov K, Stoyanova P. Razpredelyane na trafika po marshruti $v$ transportna mrezha s tegla na dagite razmiti chisla, 'Mehanika Transport Komunikatsii': 3/ 2015, art. 1144.

[4] Klein, C. M. Fuzzy Shortest Paths, Fuzzy Sets and Systems 1991, 39, 27-41.

[5] Kung J. Y., Chuang T. N., The shortest path problem with discrete fuzzy arc lengths. Computers and Mathematics with Applications, 2005, 49, 263-270.

[6] Okada S., Soper T. A shortest path problem on a network with fuzzy lengths, Fuzzy Sets Syst, 2000, 109, 129-140.

[7] Raykov R., Kachaunov T., Karagaozov K. Optimizatsiya na razpredelenieto na vagonopototsite $v$ zhelezopatniya transport. Conference "Prilozhenie na EIM i mikroprotsesornata tehnika v zhelezopatniya transport", Varna, 21-22 october 1983).

[8] Sheffi Y., Urban transportation networks, Urban transportation-Mathematical models, 1984.

[9] Stoyanova P., Karagyozov K. Research On The Coverage Of Emergency Medical Aid Canters By Number And Location In Accordance With Stated Urgency Standards, "Mechanics Transport Communications": 3 / 2016, art. 1306.

[10] Wardrop J. G., Whitehead J. I. Correspondence. Some Theoretical Aspects of Road Traffic Research. ICE Proceedings: Engineering Divisions, 1952, 1 (5): 767.

[11] Yadav A., Biswas B. On Searching Fuzzy Shortest Path In a Network, International Journal of Recent Trends in Engineering, 2009, Vol 2, No 3, 16-18.

[12] Yen, Jin Y. An algorithm for finding shortest routes from all source nodes to a given destination in general networks, Quarterly of Applied Mathematics, 1970, 27: 526-530.

[13] Zadeh L. A. Fuzzy sets. Information and Control, 1965, 8, 338-353. 